Available online at GSC Online Press Directory

GSC Biological and Pharmaceutical Sciences

e-ISSN: 2581-3250, CODEN (USA): GBPSC2

Journal homepage: https://www.gsconlinepress.com/journals/gscbps

(RESEARCH ARTICLE)

\title{
Chemical composition, antioxidant and antimicrobial activities of Capsicum annuum var. annuum concentrated extract obtained by reverse osmosis
}

\author{
Oulaï Ayamaé Casimir 1, 2, Djè Kouakou Martin ${ }^{2,}{ }^{*}$, Eba Krou Philippe ${ }^{3}$, Adima Amissa Augustin ${ }^{1}$ and \\ Kouadio Eugène Jean Parfait ${ }^{1}$ \\ ${ }^{1}$ Houphouët-Boigny National Polytechnic Institute (INP-HB), Laboratory of Industrial Processes, Synthesis and New \\ Energies (LAPISEN) - Chemistry Unit for Water and Natural Substances (UCESNA) / Polyphenol Group, BP 1313 \\ Yamoussoukro, Côte d'Ivoire. \\ ${ }^{2}$ Laboratory of Biocatalysis and Bioprocesses, Training and Research Unit in Food Sciences and Technology, Nangui \\ Abrogoua University, 02 BP 801 Abidjan 02, Côte d'Ivoire. \\ ${ }^{3}$ Laboratory of Food Biochemistry and Tropical Products Technology, Nangui Abrogoua University, UFR/STA, 02 BP 801 \\ Abidjan 02, Cote d'Ivoire.
}

Publication history: Received on 25 October 2018; revised on 14 November 2018; accepted on 19 Novmber 2018

Article DOI: https://doi.org/10.30574/gscbps.2018.5.2.0123

\begin{abstract}
The purpose of this study was to assess Chemical composition, total flavonoid and carotenoid contents with antioxidant and antimicrobial activities in crude and concentrated extracts of pepper fruit (Capsicum annuum var an.). The concentrated extract was obtained by reverse osmosis process. Radical scavenging potential was also determined using in vitro assay: 1, 1-diphenyl-2-picrylhydrazyl (DPPH) radicals. The GC-MS analysis of concentrated extracts of $C$. annuum revealed the presence of major constituents such as lactic acid, valeric acid, 5-methoxy, butanedioic acid, phenylalanine, hexadecanoic acid, ethyl ester, 6-methoxy-hexane-2-ol, butane, 2,3diol, pentanoicacid,4-oxo-, 3-methyl-2-hydroxyl butanoic acid, benzeneacetic acid, 4-hydroxyl, 1,2-benzenedicarboxylic acid ester, 2,5-furandicarboxylic acid, 7hydroxyl7-methyloctanoïc acid. Furthermore, the results indicated that the total flavonoid (3.7 $\pm 0.1 \mathrm{~g} / \mathrm{L} \mathrm{Eq} \mathrm{Quercetin)}$ and total carotenoid $(54.33 \pm 1.1 \mathrm{mg} / 100 \mathrm{~mL}$ of fresh extract) contents and the antioxidant activities $((83.44 \pm 0.98 \%)$ in concentrated extract of $C$. annuum fruit were significantly $(\mathrm{p} \leq 0.05)$ higher than those recorded in crude extract. They also showed that the MIC values ranged from 10 to $20 \mu \mathrm{g} / \mathrm{mL}$. This confirmed the existence of significant activity against the bacterial strains tested. Our results revealed that Gram positive and negative microorganisms were affected by the tested concentrated extract. Moreover, this study indicated that the concentrate of the Capsicum annuum fruit effectively shows the best ability to scavenge the free radicals. This concentrated extract also presents some antimicrobial activity against six microorganisms.
\end{abstract}

Keywords: C annuum; Concentrated extract; Reverse Osmosis; GC-MS; Antioxidant; Antimicrobial activity

\section{Introduction}

Pepper, specifically Capsicum annuum an. is the general name for plants coming from Capsicum species of Solanaceae family, native to southern North America and northern South America. It is an important agricultural crop, not only because of its economic importance, but also for the nutritional value of its fruits, mainly due to the fact that they are an excellent source of natural colours and antioxidant compounds [1-2]. Indeed, antioxidant nutrients play an important role in health maintenance. They neutralize harmful chemicals called "free-radicals" that cause cell damage in the body. Antioxidants have been strongly linked to the protection from numerous diseases, heart disease to cancer, eye disease to regulation of the immune system. Pepper is an important nutrient for human diet due to its contained vitamins and

\footnotetext{
${ }^{*}$ Corresponding author

E-mail address: kmartindje@yahoo.fr
} 
antioxidants. In particular, the antioxidant vitamins (vitamins A, C, and E), carotenoids are present in high concentrations in various types of pepper. Ascorbic acid (vitamin C) is the biologically active form of dehydroascorbic acid diseases. It is fundamentally provided by fruits and vegetables. Fresh pepper contains a higher amount of ascorbic acid than the other fruits and vegetable and it prevents some important illness such as cancer, anaemia, diabetics, and cardiovascular. It is also a good source of phenolic compounds such as flavonoids but the phenolics composition determined in pepper fruits is incomplete. Indeed, flavonoid compounds were known as antioxidant agent. This agent was benefit for people health. Several researches showed that high concentrations of flavonoids were significantly associated with reduced risk of cardiovascular disease through an improvement in vascular function and a modulation of inflammation [3-4]. Moreover, they could protect cell and tissue damage from free radicals by potent antioxidant capacity [5]. Flavonoids are phytochemical ubiquitous found in plants with a wide group of exploitable activities, including antimicrobial activity, antibiotic synergism and bacterial virulence removal [6]. Otherwise, hot peppers are the only plants that are able to produce capsaicinoids, responsible for their characteristic hot taste. The concentrations of these compounds depend on cultivar, maturity, growing conditions, and postharvest manipulation. Perera and Yen [7] reported that consumption of carotenoid rich foods reduces the incidence of several disorders such as cancers, cardiovascular diseases, age-related macular degeneration, cataracts, diseases related to compromise immune function, and other degenerative diseases. The importance of the carotenoid compounds in the diet has been recognized, not only as precursors of vitamin A but also as antioxidants in cell protection and in the prevention of degenerative diseases [8]. Carotenoids are fat soluble antioxidants found in many fruits and vegetables and are required for human epithelial cellular differentiation [9]. Furthermore, recent reports state that the Capsicum genus, among other plant genera, is a good source of antimicrobial and antifungal compounds [10].

Despite the beneficial assets available to the pepper, various alterations compromise its quality. Relevant conservation operations to their main quality characteristics are therefore necessary. Otherwise, the lack of effective conservation of these seasonal products causes cyclical shortages in the year. These losses are estimated at 20 to $40 \%$ for these products [11]. Indeed, the effectiveness of preservation technique is measured in terms of the quality of product (hygienic, nutritional, sensory...). Membrane separation processes such as Tangential Microfiltration (MFT) and Reverse Osmosis (RO) have been developed and appear important to resolve this situation. Membrane technology in vegetable treatment has significant progresses in recent years. It is used to the conventional processes for juice concentration and clarification [12]. It has many advantages over traditional separation processes. In general, separation occurs at ambient temperature, with no phase change and without using a heat source, resulting in considerable energy savings and avoiding oxidation and degradation of thermolabile compounds [13]. Reverse osmosis (R0) was used for the concentration of fruit extract with promising considering the quality of the obtained products. Promising results were achieved with sugar solution concentration from 15 to $50^{\circ}$ Brix. In this configuration, reverse osmosis occupies the first stage [14].

Although pepper fruit possesses a great edible plant biodiversity, there is a serious lack of information a on its concentrated extract by RO. Therefore, the present study has been undertaken to assess the chemical composition, total flavonoid and carotenoid contents in pepper concentrated extract obtained by RO. Moreover, the antioxidant activity was estimated by DPPH radical scavenging assay followed by evaluation of the antimicrobial activity against six common food borne pathogens. Thus, this concentrated extracts could be used as fundamental data for nutritionists or public health workers to recommend consumers the appropriate types of peppers Capsicum concentrated extracts for their health needs.

\section{Material and methods}

\subsection{Plant material}

Fruits of sweet pepper (C. annuum var.an.) were grown in an experimental field (INPHB Yamoussoukro, Côte d'Ivoire) under tropical climate conditions. The peppers were harvested at the maturity stage (fully red). After harvest, the fruits were immediately transported in the laboratory (LAPISEN, INPHB Yamoussoukro, Côte d'Ivoire). Then, the peppers were carefully selected to ensure that fruits free of defects were chosen.

\subsection{Crude extract clarification and concentrate processes}

\subsubsection{Extraction of crude extract}

The maceration and bioprocesses membrane separation was carried out according to method of Adjé et al. [15]. Fresh fruits were carefully washed and crushed. The maceration of pepper fruits was performed in two steps. Firstly, $5 \mathrm{~kg}$ of fresh plant material were macerated into 100 liters of aqueous ethanol (70:30 v/v) to obtain ethanolic extract. Aqueous 
extracts were produced by the same weight ( $5 \mathrm{~kg}$ ) in 100 liters aqueous solution. The maceration was slightly stirred to wet completely the crushed material and let for $24 \mathrm{~h}$ maceration time at room temperature. The crude extract was successively pre-filtered through a fine sieve (pore diameter of $1 \mathrm{~mm}$ ) and a nylon fabric lower porosity (pore diameter $=25 \mu \mathrm{m}$ ). Thus, crude extract (CE) is obtained.

\subsubsection{Crude extract clarification process}

The clarification of crude extract was conducted in the microfiltration (MF) unit featured a ceramic multichannel membrane (P19-40, France) that had a total effective filtration area of $0.24 \mathrm{~m}^{2}$ and an average pore diameter of $0.2 \mu \mathrm{m}$. Transmembrane pressure for feeding is set at 1.2 bar, and the CE was clarified against a transmembrane pressure of 0.6 bar. All trials were carried out with continuous crude product feed and permeate collection at flow. The feed-and-bleed procedure was also followed in the long term trials by implementing continuous extraction of retentate at flow. Thus, the clarified extract is obtained.

\subsubsection{Concentrate process}

The concentrate was obtained by reverse osmosis (RO). Reverse osmosis was performed with a composite polymer membrane of type SW 30-2540 (Filmtec) from Polymem (France). The characteristics of which were effective membrane area of $2.5 \mathrm{~m}^{2}$. The operation conditions were 40 bar of transmembrane pressure and temperature of $30{ }^{\circ} \mathrm{C}$. The extract circulated inside the fibers. The loop was continuously fed with cold clarified extract $\left(20^{\circ} \mathrm{C}\right)$. The both sample crude extract (CE) and concentrate (C) were lyophilized. Then, $5 \mathrm{~g}$ of each lyophilized extract are added to 20 $\mathrm{mL}$ of water and homogenized for $3 \mathrm{~h}$ at room temperature. Those ethanolic extracts $(0.25 \mathrm{~g} / \mathrm{mL})$ were analyzed.

\subsection{GC-MS analytical conditions of the concentrate}

Within a three necked round bottom flask containing aqueous methanol (25 mL, 95\%) and 25 mL of hydrochloric acid ( $3 \mathrm{M}$ ) was added to $0.5 \mathrm{~g}$ of freeze dried sample. The mixture was refluxed in a water bath at $90{ }^{\circ} \mathrm{C}$ for $2 \mathrm{~h}$ and cooled. In separator funnel containing the mixture, ethyl acetate $(3 \times 50 \mathrm{~mL})$ was then added to recover the aglycones of 0 -glycosyl compounds. Anhydrous (MgSO4) was added to remove moisture, filtered and evaporated of the solvent.

In general, the hydrolysis extract contain groups (phenols, alcohols and carboxylic acids) which can be derivatised to improve the chromatographic properties and separation on the GC-column. The most common derivatisation procedure of compounds containing-OH and-COOH groups are silylation. Among the many possibilities of silylating agents. Derivatisation experiments were performed by considering BSTFA. For the silylation procedure, a mixture of N.0-bis (trimethylsilyl) trifluoroacetamide BSTFA $(0.5 \mathrm{~mL})$ and dichloromethane $(0.5 \mathrm{~mL})$ were added to $10 \mathrm{mg}$ of residue (extract with ethyl acetate after hydrolysis). The mixture was placed in a water bath at $70{ }^{\circ} \mathrm{C}$ for 1 hour. The silylated samples were injected into a GC-MS system (Shimadzu-QP2010SE) consisted of a gas chromatograph coupled with a mass spectrometer (quadrupole) in the EI (Electron Impact) brand fitted with a split/split less injector. Capillary column low bleed Zebron ZB-WAX $(20 \mathrm{~m} \times 0.18 \mu \mathrm{m})$ was used. The flow rate of carrier gas (helium) was maintained at $0.9 \mathrm{ml} / \mathrm{min}$. The injector temperature was $280^{\circ} \mathrm{C}$. The own temperature increased from 70 to $270^{\circ} \mathrm{C}$ with $4{ }^{\circ} \mathrm{C} / \mathrm{min}$ and then held to $270{ }^{\circ} \mathrm{C}$ for $20 \mathrm{~min}$. The detector temperature was $290{ }^{\circ} \mathrm{C}$. Identification of components was based on comparison of their mass pectra with those of Wiley and NIST libraries and those described by Adams as well as on comparison of their retention indices with literature [9].

\subsection{Determination of total flavonoid content}

The total flavonoid content was determined according to the method of Ying and Wan [16]. 1 mL of extract aliquot was added to $0.3 \mathrm{~mL}$ of $5 \%$ sodium nitrite $\left(\mathrm{NaNO}_{2}\right)(\mathrm{w} / \mathrm{v})$ and $0.3 \mathrm{~mL}$ of $10 \%$ aluminum chloride $\left(\mathrm{AlCl}_{3}\right)(\mathrm{w} / \mathrm{v})$. After $6 \mathrm{~min}$ of incubation at ambient temperature, $2 \mathrm{~mL}$ of sodium hydroxide $(\mathrm{NaOH})$ was added to the mixture. The final volume was brought up to10 $\mathrm{mL}$ by adding aqueous ethanol and then mixed. The obtained mixture was incubated at ambient temperature for $15 \mathrm{~min}$ and then the absorbance against blank was determined at $510 \mathrm{~nm}$ ((Spectrophotometer, Type JASCO UV-500, Japan). Quercetin was used as standard for the calibration curve. Total flavonoid content was calculated as gram quercetin equivalent per liter (gQE/L) fresh pepper extract. All samples were performed in triplicate.

\subsection{Determination of total Carotenoid content}

Total carotenoid content was quantified according to the method of Rodriguez-Amaya and Kimura [17]. $10 \mathrm{~g}$ of each sample (CE or C), lyophilized previously, were dissolved in $20 \mathrm{~mL}$ acetone and the supernatant decanted. The sample was filtered and washed with $30 \mathrm{~mL}$ acetone. Then, the acetone was evaporated. This procedure was repeated four times until no residual solvent remained. The obtained dry sample was dissolved in $60 \mathrm{~mL}$ petroleum ether. The mixture was filtered, transferred quantitatively to a $100 \mathrm{~mL}$ volumetric flask and volume was adjusted with petroleum ether. $2 \mathrm{~mL}$ 
of the obtained mixture were collected in a test tube with $8 \mathrm{~mL}$ petroleum ether. Absorbance was read at $450 \mathrm{~nm}$ (Spectrophotometer, Type JASCO UV-500, Japan) and Total carotenoid content was calculated with a $\beta$-carotene curve.

\subsection{Evaluation of the antioxidant activity via DPPH radical scavenging assay}

Antioxidant activity of $C$. annuum extract was measured as scavenging free radical potential in methanolic solution of DPPH (1,1-diphenyl-2-picrylhydrazyl), according to the method of Schmeda-Hirschman [18]. To $2.4 \mathrm{~mL}$ from $0.25 \mathrm{~g} / \mathrm{mL}$ of each sample of crude extract (CE) and concentrate (C), $0.8 \mathrm{~mL}$ of $0.1 \mathrm{mM}$ DPPH (methanol) was added, vortexed and followed by incubation at room temperature for 10 minutes. The control sample was prepared without any extract or fraction. The decrease in absorbance in presence of DPPH was measured at $517 \mathrm{~nm}$ by using Spectrophotometer (Type JASCO UV-500, Japan). Absorption of a blank sample containing the same amount of methanol and DPPH solution acted as the control.

$$
\% \text { DPPH inhibition activity }=\left[\mathrm{A}_{0}-\mathrm{A}_{1} / \mathrm{A}_{0}\right] \times 100[1]
$$

Where: $A_{0}$ is the absorbance of the control and

$A_{1}$ is the absorbance of the sample.

Ascorbic acid was used as a positive control. Samples were analyzed in triplicate.

\subsection{Antimicrobial assay}

\subsubsection{Microbial strains}

The microbial strains used belong to Gram positive bacteria (Staphylococcus aureus UFPEDA02, Enterococcus faecalis ATCC6057, and Bacillus subtilis UFPEDA86) and Gram negative bacteria (Escherichia coli ATCC25922, Pseudomonas vulgaris, Pseudomonas aeruginosa UFPEDA416). The samples were acquired from the Antibiotics Department of the University Federal of Pernambuco, Recife, Brazil.

\subsubsection{Determination of minimal inhibitory concentration (MIC)}

The broth micro-dilution assay was performed according to CLSI reference methods M7-A6 for bacteria (2003). Ninetysix-well microplates were used to obtain the MIC value of concentrated extract from $C$. annuum against microorganisms. The MIC was determined by measuring each well with a microplate reader (ASYS UVM 340, Cambridge, UK). The MIC was defined as the lowest sample concentration that inhibited bacterial growth compared with the optical density of the controls. Chloramphenicol $(50 \mu \mathrm{g} / \mathrm{mL})$ was used as a positive control for all of the strains.

\subsection{Statistical analysis}

All analyses were performed in triplicates. Results were expressed by means of \pm standard deviation (SD). Means were separated according to student test $(\mathrm{p} \leq 0.05)$, with the help of the software Statistica 7.1 (StatSoft Inc, Tulsa USA Headquarters).

\section{Results and discussion}

\subsection{Chemical composition of the concentrate}

The GC-MS analysis of concentrated extract of $C$. annuum revealed the presence of 28 compounds representing different classes (Table 1, Fig 1.). The constituents such as lactic acid, valeric acid, 5-methoxy, butanedioic acid, phenylalanine, hexadecanoic acid, ethyl ester, 6-methoxy-hexane-2-ol, butane, 2, 3 diol, pentanoic acid, 4-oxo-3-methyl-2-hydroxyl butanoic acid, benzeneacetic acid, 4-hydroxyl, 1, 2-benzenedicarboxylic acid ester, 2,5-furandicarboxylic acid, 7hydroxyl 7-methyloctanoïc acid, were found to be important in the concentrate. The compounds in GC-MS analysis were identified on the basis of comparison of the retention time (RT) and mass spectra with the references present in the NIST mass spectral library. In this servey, most of the identified volatile compounds were hydrocarbons, fatty acids, fatty esters and some novel constituents such as Phenylalanine. Many of these identified compounds have already been reported to be pharmacologically active. Indeed, hexadecanoic acid is known to have potential antibacterial and antifungal activities [19]. 


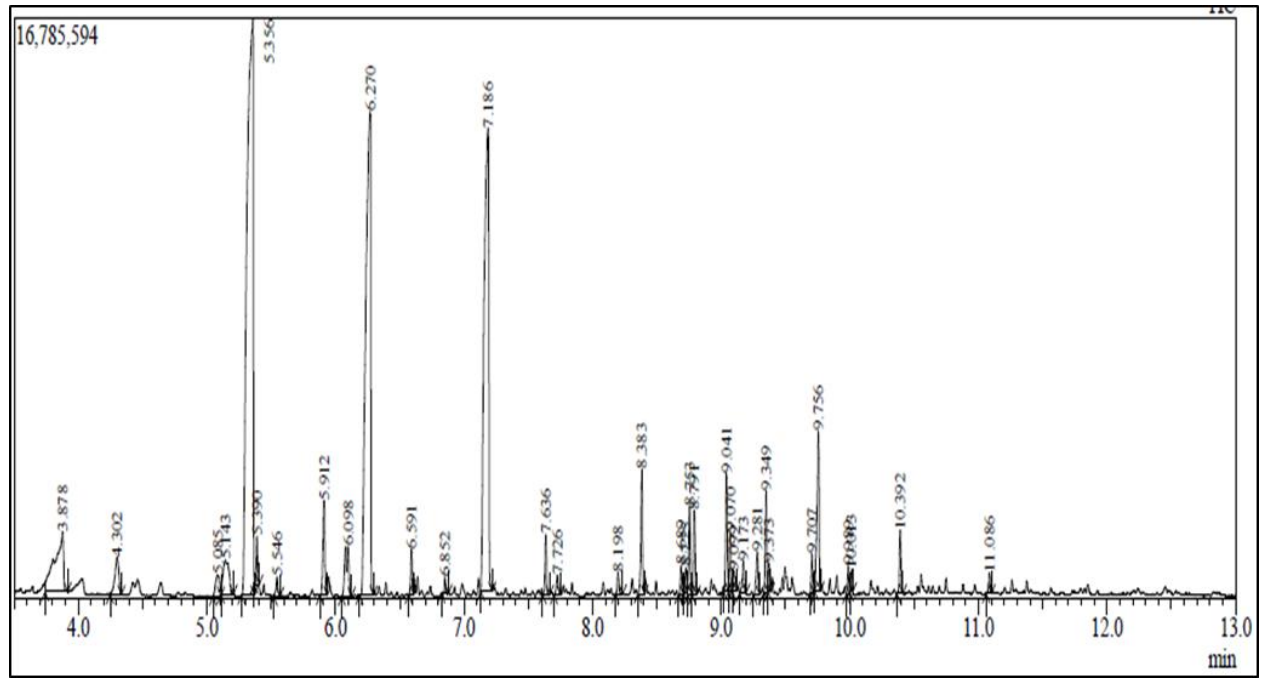

Figure1GC-MSchromatogram related to compounds of $C$. Annuum concentrated extract

Table 1Chemical composition of concentrated extract of Fresh Capsicum fruits analyzed by GC-MS

\begin{tabular}{|c|c|c|c|c|}
\hline No & Nameofcompounds & $\begin{array}{l}\text { Molecular } \\
\text { formula }\end{array}$ & $\begin{array}{l}\text { Retention time } \\
\text { (min) }\end{array}$ & $\begin{array}{c}\text { Peakarea } \\
\text { (\%) }\end{array}$ \\
\hline 1 & Phenylalanine & $\mathrm{C}_{9} \mathrm{H}_{11} \mathrm{NO}_{2}$ & 3,878 & 4.51 \\
\hline 2 & 6-Methoxy-hexane-2-ol & $\mathrm{C}_{8} \mathrm{H}_{18} \mathrm{O}_{2}$ & 4,302 & 1.25 \\
\hline 3 & 3-phenyl Butane-2-ol & $\mathrm{C}_{10} \mathrm{H}_{14} \mathrm{O}$ & 5,085 & 0.75 \\
\hline 84 & Butane, 2,3 diol & $\mathrm{C}_{4} \mathrm{H}_{10} \mathrm{O}_{2}$ & 5,143 & 1.73 \\
\hline 5 & Lactic acid & $\mathrm{C}_{3} \mathrm{H}_{6} \mathrm{O}_{3}$ & 5,356 & 30.90 \\
\hline 6 & ethyl malonate & $\mathrm{C}_{5} \mathrm{H}_{4} \mathrm{O}_{4}$ & 5,390 & 0.52 \\
\hline 7 & Acetamide & $\mathrm{CH}_{3} \mathrm{CONH}_{2}$ & 5,546 & 0.30 \\
\hline 8 & Pentanoic acid, 4-oxo- & $\mathrm{C}_{5} \mathrm{H}_{8} \mathrm{O}_{3}$ & 5.912 & 1.67 \\
\hline 9 & 3-methyl-2-hydroxyl Butanoic acid, & $\mathrm{C}_{5} \mathrm{H}_{10} \mathrm{O}_{3}$ & 6.098 & 1.56 \\
\hline 10 & Valeric acid, 5-methoxy & $\mathrm{C}_{5} \mathrm{H}_{10} \mathrm{O}_{2}$ & 6,270 & 20.49 \\
\hline 11 & 2-Hydroxyisocaproicacid & $\mathrm{C}_{6} \mathrm{H}_{12} \mathrm{O}_{3}$ & 6.591 & 0.64 \\
\hline 12 & alpha.-D-Galactopyranose & $\mathrm{C}_{6} \mathrm{H}_{12} \mathrm{O}_{6}$ & 6.852 & 0.17 \\
\hline 13 & Butanedioic acid & $\mathrm{C}_{4} \mathrm{H}_{6} \mathrm{O}_{4}$ & 7.186 & 18.56 \\
\hline 14 & Benzoic acid & $\mathrm{C}_{7} \mathrm{H}_{6} \mathrm{O}_{2}$ & 7,726 & 0.36 \\
\hline 15 & 2-Hydroxy-4-methylpentanoic acid & $\mathrm{C}_{6} \mathrm{H}_{12} \mathrm{O}_{3}$ & 8,198 & 0.29 \\
\hline 16 & Benzeneacetic acid, 4-hydroxyl & $\mathrm{C}_{8} \mathrm{H}_{8} \mathrm{O}_{3}$ & 8,383 & 1.78 \\
\hline 17 & D-Erythro-Pentopyranose, 2-deoxy- & $\mathrm{C}_{8} \mathrm{H}_{8} \mathrm{O}_{3}$ & 8,689 & 0.39 \\
\hline 18 & 1,2-Benzenedicarboxylic acid, ester & $\mathrm{C}_{24} \mathrm{H}_{38} \mathrm{O}_{4}$ & 8,753 & 1.15 \\
\hline 19 & 2,5-Furandicarboxylic acid & $\mathrm{C}_{6} \mathrm{H}_{4} \mathrm{O}_{5}$ & 8,791 & 1.20 \\
\hline 20 & Hexadecanoic acid, ethyl ester & $\mathrm{C}_{18} \mathrm{H}_{36} \mathrm{O}_{2}$ & 9,041 & 1.72 \\
\hline 21 & Pentanoic acid, 4-methyl- & $\mathrm{C}_{6} \mathrm{H}_{12} \mathrm{O}_{2}$ & 9.070 & 0.65 \\
\hline 22 & Benzeneacetic acid, & $\mathrm{C}_{8} \mathrm{H}_{8} \mathrm{O}_{2}$. & 9.099 & 0.38 \\
\hline 23 & 2-deoxyD-Erythro-Pentopyranose & $\mathrm{C}_{5} \mathrm{H}_{10} \mathrm{O}_{4}$ & 9.281 & 0.75 \\
\hline 24 & 7-hydroxyl 7-methyloctanoïc acid & $\mathrm{C}_{15} \mathrm{H}_{34} \mathrm{O}_{3}$ & 9.349 & 1.29 \\
\hline 25 & phtalic acid & $\mathrm{C}_{24} \mathrm{H}_{38} \mathrm{O}_{4}$ & 9.373 & 0.32 \\
\hline 26 & 2,5-Furandicarboxylic acid & $\mathrm{C}_{6} \mathrm{H}_{4} \mathrm{O}_{5}$ & 9.707 & 0.45 \\
\hline 27 & 2,5-Furandicarboxylic acid & $\mathrm{C}_{6} \mathrm{H}_{4} \mathrm{O}_{5}$ & 9.989 & 0.36 \\
\hline 28 & Hexadecanoic acid, ethyl ester & $\mathrm{C}_{18} \mathrm{H}_{36} \mathrm{O}_{2}$ & 11.08 & 0.30 \\
\hline
\end{tabular}

RT- Retention time 
It is a saturated fatty acid. Many fatty acids have antibacterial and antifungal properties and could modulate immune responses by acting directly on cells [20]. Hexadecanoic acid and methyl ester have antioxidant and anticancer properties respectively [21]. 2,5-Furandicarboxylic acid (FDCA) also shows antibacterial activity and is the main ingredient of antimicrobial food additives and some antibacterial herbs [22]. Screening studies on FDCA-derived anilides showed their important anti-bacterial action.

The diacid itself is a strong complexing agent, chelating ions such as $\mathrm{Ca}^{2+}, \mathrm{Cu}^{2+}$ and $\mathrm{Pb}^{2+}$. It is used in medicine to remove kidney stones [23]. Hydroxy-isocaproic acid (HICA), also known as leucic acid or DL-2-hydroxy-4-methylvaleric acid, is an end product of leucine metabolism in human tissues such as muscle and connective tissue. According to the clinical and experimental studies, HICA could be considered as an anti-catabolic substance [21]. It is a physiological agent which is normally present in the human body in small amounts. Otherwise, it may be noted that this pepper species is rich in secondary metabolites, similar to other medicinal plants [21]. Among the secondary metabolites identified in Capsicum annuum exercising a wide range of biological activities on humans, may be listed: pentanoicacid, 4-oxo; acetamide, ethylmalonate, valeric acid, 5-methoxy. These compounds were tested for their antimicrobial, anti-inflammatory, antioxidant, anti-cancer and hepatoprotective activities [24].

Moreover, acetamide derivatives have excellent antibacterial and antifungal activities [25]. The organic acids which include lactic acids don't only lower the $\mathrm{pH}$, thereby affecting the growth of pathogen, but they can also be toxic to the microbes [26].The presence of bioactive phyto-constituents is crucial in the well-known pharmacological activities shown by concentrate.

\subsection{Antimicrobial activity}

Antimicrobial activity of ethanolic extract of $C$. annuum fruit was tested against six microorganisms. These were two (03) Gram negative bacteria (P. aeruginosa P. vulgaris and E. coli) and three (03) Gram positive bacteria (E. faecalis, B. subtilis and $S$. aureus). The results of the minimal inhibitory concentration (MIC) examined against different pathogenic microorganisms are shown in Table 2. They indicated that the obtained MIC values confirmed the existence of significant activity against the bacterial strains tested in our study, with MIC values ranging from 10 to $20 \mu \mathrm{g} \mathrm{mL}^{-1}$. Our results showed that Gram positive and negative microorganisms were affected by the tested concentrated extract. Similar study was performed by Careaga et al. [27], who investigated the antimicrobial effect of Capsicum extract on P. aeruginosa inoculated in minced beef and observed a reduction of $P$. aeruginosa growth, with a bacteriostatic effect.

A previous study carried out by Molina-Torres et al. [28] required MIC values of $300 \mu \mathrm{g} / \mathrm{mL}^{-1}$ and $25 \mu \mathrm{g} \mathrm{mL} \mathrm{L}^{-1}$ to inhibit E. coli and B. subtilis growth, with capsaicin. Our findings were agreement with the findings of the previous study for $S$. aureus [29]. One the other hand, they were disagreement with the observations for E. coli [30]. Furthermore, the antimicrobial activity of highly polar ethanol extracts of $C$. frutescens pepper was already reported against a number of microorganisms $[31,32]$. The significant antimicrobial activities may be attributed to the compounds identified in the GC-MS analysis such as lactic acid (30.90\%), valeric acid (20.49\%) and 5-methoxy butanedioic acid (18.56\%) which were found as the major constituents [33]. The isolation of these antimicrobial agents from capsicum fruit could lead to an important change in the area of food safety and may be used in the prevention of food-borne diseases.

Table 2Minimal inhibitory concentration (MIC) of ethanolic extracts to six microorganisms

\begin{tabular}{cll}
\hline \multicolumn{2}{c}{ Microorganisms } & MIC $(\boldsymbol{\mu g} / \mathbf{m l})$ \\
\hline Gram positive & Enterococcus faecalis & 15 \\
bacteria & Bacillus subtillis & 20 \\
& Staphylococcus aureus & 20 \\
\hline Gramnegativebacteria & Pseudomonas vulgaris & 10 \\
& P. aeruginosa & 15 \\
& Escherichia coli & 16 \\
\hline
\end{tabular}

\subsection{Total flavonoid and carotenoid contents and antioxidant activities}

Total flavonoid and total carotenoid contents with the antioxidant activities in crude extract (CE) and concentrate (C) of Capsicum annuum fruit, are shown in table 3. The results indicated that obtained total flavonoid and total carotenoid contents and antioxidant activities in crude extract of $C$. annuum differed significantly ( $\leq \leq 0.05)$ from those found in 
concentrate(C) of $C$. annuum fruit. Indeed, they revealed that the flavonoid content in concentrate $(3.7 \pm 0,10 \mathrm{~g} / \mathrm{L} \mathrm{Eq}$ Quercetin) was significantly $(\mathrm{p} \leq 0.05)$ higher than that observed in the crude extract $(1.11 \pm 0.04 \mathrm{~g} / \mathrm{L} \mathrm{Eq} \mathrm{Quercetin)}$. Considering the nature of solvent, our study showed that ethanol was able to extract a higher proportion of flavonoid and carotenoid compounds from $C$. annuum. Similar observation was shown by Chinn et al. [34], who noted that the choice of solvent should be made according to the degree of solubility of pigments and that is a major factor influencing the molecule extraction process. Otherwise, total carotenoid content in concentrate $(54.33 \pm 0.05 \mathrm{mg} / 100 \mathrm{~mL}$ of fresh extract) differed meaningfully $(\mathrm{p} \leq 0.05)$ from that obtained in crude extract $(35.6 \pm 0.3 \mathrm{mg} / 100 \mathrm{~mL}$ of fresh extract). The differences in carotenoid content may be due to the influence of genotype and maturity stages and processing.

As for the antioxidant activities, significant variations between crude extract and concentrate were observed. They were found to be high $(83.44 \pm 0.98 \%)$ in concentrated of Capsicum annuum fruit. Our results suggest that the concentration procedure was efficient. Reverse osmosis (RO) is a cold-operated process that presents an interesting alternative to heat treatments for highly heat sensitive bioproducts, in particular to preserve their original functionalities and activities. RO is used to preserve bioactivities have to be kept [35]. The results were agreement with those obtained by Cao and Prior [36], who identified bell-pepper with strong antioxidant activity using oxygen radical absorbance capacity (ORAC) assay. They indicated correlation between antioxidant activity and this compound. According to Khokhar and Apenten [37], the antioxidant activity could be influenced by the presence of hydroxyl group. Indeed, the antioxidant activity is also very dependent on the number and position of the hydroxyl group presence in the molecules [38]. It appeared a strong correlation between the both parameters (flavonoid ( $\mathrm{r}=0.82$ ) and carotenoid ( $\mathrm{r}=0.91)$ ) and antioxidant activity in concentrated extract. The report of Esmaeili et al. [39] corroborated correlation between the flavonoid and carotenoid contents and antioxidant activities. The strong correlation between the flavonoid content and antioxidant activity was shown by Kuna et al. [40], who found a correlation coefficient of 0.86 . Some works confirmed correlation between the phenolic compounds content and the antioxidant activity [41]. On the other hand, others studies didn't find correlation between the both parameters (flavonoid and carotenoid contents) and antioxidant activities or low correlation [42]. This observed in crude extract. Otherwise, flavonoids are the main class of chemical compounds found in with antioxidant activity [43]. Recent studies showed that flavonoids contributed significantly to the scavenging activity of vegetable $[44,45]$. Indeed, Flavonoids are naturally occurring in plants and are thought to have positive effects on human health. Studies on flavonoidic derivatives revealed a wide range of antibacterial, antiviral, anticancer and anti-allergic activities [36]. Moreover, flavonoids had highly effective scavengers of most oxidizing molecules, including singlet oxygen, and various free radicals implicated in several diseases [37]. Our results corroborated the findings in the literature for other extracts of plant products [47]. They suggested that phenolic acids and flavonoids may be the major contributors for the antioxidant activity.

Table 3Total flavonoid and carotenoid contents with antioxidant activities in crude and concentrated extracts from pepper (Capsicum annuum var an) fruit

\begin{tabular}{llc}
\hline Parameters & \multicolumn{2}{c}{ Samples } \\
\cline { 2 - 3 } & Crude extract & Concentrated extract \\
\hline $\begin{array}{l}\text { Total flavonoid content } \\
\text { (g / L Eq Quercetin) }\end{array}$ & $1.10 \pm 0.04^{\mathrm{a}}$ & $3.70 \pm 0.10^{\mathrm{b}}$ \\
$\begin{array}{l}\text { Total carotenoid content } \\
\text { (mg/100mL of fresh extract) }\end{array}$ & $35.60 \pm 0.03^{\mathrm{a}}$ & $54.33 \pm 1.10^{\mathrm{b}}$ \\
Antioxidant activity (\%) & $59.53 \pm 0.54^{\mathrm{a}}$ & $83.44 \pm 0.98^{\mathrm{b}}$ \\
\hline
\end{tabular}

All analyses were performed in triplicates and the values in the table are the mean \pm standard deviation. $0 \mathrm{n}$ the same line, the means followed by a similar letter aren't significantly different $(\mathrm{p} \leq 0.05)$ according to the Student's test.

\section{Conclusion}

This study showed that concentrated extracts of $C$. annuum contained the major constituents such as lactic acid, valeric acid, 5-methoxy, Butanedioic acid, Phenylalanine, Hexadecanoic acid, ethyl ester, 6-Methoxy-hexane-2-ol, Butane, 2,3diol, Pentanoic acid, 4-oxo-, 3-methyl-2-hydroxylButanoic acid, Benzeneacetic acid,4-hydroxyl, 1,2Benzenedicarboxylic acid ester, 2,5-Furandicarboxylic acid, 7-hydroxyl7-methyloctanoïc acid. The studied concentrate from the Capsicum annuum fruit is good sources of flavonoids and carotenoids. Furthermore, these parameters contents and antioxidant activity was found to be higher in concentrate than those obtained in crude extract. The study also showed that Gram positive and negative microorganisms were affected by the tested concentrated extract. Capsicum fruit used as concentrated extracts, increase nutritional value in different foods and diets. Concentrate of fresh peppers fruits generally may provide the types of nutritional and health benefits associated with the consumption of pepper 
fruits extract. Development and consumption of Capsicum pepper extract with high antioxidant activity may help in decreasing the incidence of certain types of diseases in humans. On the other hand, we found the best antimicrobial activity against the bacteria tested with the Capsicum extract obtain by reverse osmosis.

These findings suggest that future investigations could be performed in order to evaluate the stability of compounds of concentrate for preservation time of their potential health and food-protecting benefits or to identify other possible biological and industrial applications.

\section{Compliance with ethical standards}

\section{Acknowledgments}

Authors are grateful to anonymous reviewers for their constructive comments, which helped in improving the manuscript.

\section{Disclosure of conflict of interest}

Authors declared that there is no conflict of interest.

\section{References}

[1] Conforti F, Giancarlo AS and Menichini F. (2007). Chemical and biological variability of hot pepper fruits (Capsicum annuum var. Acuminatum L.) in relation of maturity stage. Food Chemistry, 102, 1096-1104.

[2] Deepa N, Kaur C, George B, Singh B and Kapoor HC. (2007). Antioxidant constituents in some sweet pepper (Capsicum annuum L.) genotypes during maturity. LWT Food Sciences Technology, 40, 121-129.

[3] Yi-Tzu Chen and Kuo-WeiLin (2007). Effects of heating temperature on the total phenolic compound, antioxidative ability and the stability of dioscorin of various yam cultivars. Food Chemistry, 101(3), 955-963.

[4] Neil H and Mermelsein (2008). Determining antioxdant activity. Food Technology, 11, 63-66.

[5] Petrung T, Jitpisut Junthong-oon and etal (2012). Comparative study of antioxidant activity and total phenolic Content of ethanolic extracts of ginger, black pepper and long pepper. Prc. of 1st Conference on Graduate Student Network of Thailand (GS- NETT 2012).18 DEC.

[6] Cushnie TPT and Lamb AJ. (2011). Recent advances in understanding the antibacterial properties of flavonoids. International Journal of Antimicrobial Agents, 38, 99-107.

[7] Perera CO and Yen GM. (2007). Functional Properties of carotenoids in human health. International Journal of Food Properties, 10 (2), 201-230.

[8] Stahl W and Sies H. (2003). Antioxidant activity of carotenoids. Molecular Aspects of Medicine, 24, 345-351.

[9] Zhang D. and Hamauzu Y. (2003). Phenolic compounds, ascorbic acid, carotenoids and antioxidant properties of Green, Red and yellow peppers. Journal of Food Agriculture and Environment, 1 (2), 22-27.

[10] Tajkarimi MM, Ibrahim SA and Cliver DO. (2010). Antimicrobial herb and spice compounds in food. Journal Food Control, 21, 1199-1218.

[11] Wiersinga R and de Jager A. (2009). In Business Opportunities in the ethiopian fruit and vegetable sector. Wageningen University and Research Centre - LEI, 46.

[12] Girard B and Fukumoto LR. (2000). Membrane processing of fruit juice and beverages: a review. Critical Reviews in Food Science, 40 (2), 91-157.

[13] Morão AEC. (2008). Transport mechanisms governing the nanofiltration of multicomponent solutionsapplication to the isolation of clavulanic acid, Universidade Téchica de Lisboa.

[14] Gul S and Harasek M. (2012). Energy saving in sugar manufacturing through the integration of environmentally friendly new membrane process for thin juice pre-concentration. Applied Thermal Engineering, 43, 128-133.

[15] Adjé FA, Lozano YF, Gernevé C, Lozano PR, Meudec E, Adima AA and Gaydou EM. (2012). Phenolic acid and flavonol water extracts of Delonix regia red flowers. Industry Crop Product, 37, 303-310. 
[16] Ying C and Wan D. (2012). Quantitative determination of total and individual flavonoids in stems and leaves of Buddleja davidii and Buddleja albiflora. Pharmacogn Mag, 8(32), 273-279.

[17] Rodriguez-Amaya DB and Kimura M. (2004). Harvest plus handbook for carotenoid analysis, harvest plus technical monograph 2. Washington DC and Cali, Colombia. International Food Policy Research Institute (IFPRI) and International Center for Tropical Agriculture (CIAT).

[18] Schmeda-Hirshman G, Rodriguez J, Theoduloz C, Astudillo S, Feresin G and Tapia A.(2003). Free radical scavengers and antioxidants from Peumus boldus Mol (Boldo). Free Radic Res, 37, 447- 452.

[19] McGraw LJ, Jager AK and Van Staden J. (2002). Isolation of antibacterial fatty acids from Schotia brachypetala. Fitoterapia, 73, 431-433.

[20] Agoramoorthy M, Chandrasekaran V and Venkatesalu MJH. (2007). Antibacterial and antifungal activities of fatty acid methyl esters of the blind-your-eye mangrove from India. Brazil Journal Microbial, 38, 739-742.

[21] Kumar PP, Kumaravel S and Lalitha C. (2010). Screening of antioxidant activity, total phenolics and GC-MS study of Vitex negundo. Afr.J. Biochem. Res, 4, 191-195.

[22] Zhou M. and Han CD. (2006). Rheology of a combined main-chain/side-chain liquid-crystalline polymer in the thermotropic and lyotropic states. Macromolecules, 39 (1), 232-242.

[23] LewkowskiJ.(2001). Synthesis, chemistry and applications of 5-hydroxymethyl-furfural and its derivatives. ARKIVOC, 17-54

[24] Olagunju JA, Fagbohunka BS, Oyedapo 00 and Abdul AIA. (2006). Effects of an ethanolic root extract of Plumbago zeylanica Linn. on some serum parameters of the rats. RPMP-Drug Dev. Molecules, 11, 268-276.

[25] Katke SA, Amrutkar SV, Bhor RJ and Khairnar MV. (2011).Synthesis of biologically active 2-chloronalkyl/arylacetamide derivatives. International Journal of Pharma Sciences and Research, 2(7), 148-156.

[26] Tambekar DH and Bhutada SA. (2010). Studies on antimicrobial activity and characteristics of bacteriocins produced by Lactobacillus strains isolated from milk of domestic animals. The Internet Journal Microbiology, 8, $1-6$.

[27] Careaga M, Fernández E, Dorantes L, Mota L and Jaramillo ME. (2003). Antibacterial activity of Capsicum extract against Salmonella typhimurium and Pseudomonas aeruginosa inoculated in raw beef meat. International Journal Food Microbial, 83, 331-335.

[28] Molina-Torres J, García-Chávez A and Ramírez-Chávez E. (1999). Antimicrobial properties of alkamides present in flavouring plants traditionally used in Mesoamerica: Affinin and capsaicin. Journal Ethnopharmacology, 64, 241-248.

[29] Owoseni AA and Ajayi A. (2010). Antimicrobial properties of ethanolic and aqueous extracts of Cymbopogon citrates on selected bacteria and fungi. Journal Medecine Appl Bioscience, 2, 64-73.

[30] Akin-Osanaiye BC, Agbaji AS and Dakare MA. (2007). Antimicrobial Activity of Oils and Extracts of Cymbopogon citratus (Lemon Grass), Eucalyptus citriodora and Eucalyptus camaldulensis. Journal of Medical Sciences, 7, 694697.

[31] Shariati A, Pordeli HR, Khademian A and Aydani M. (2010). Evaluation of the antibacterial effects of Capsicum Spp. extracts on the multi-resistant Staphylococcus aureus strains. Journal Plant Sciences Research, 5, 76-83.

[32] Koffi N R, Kouassi CK, Zinzerdof YN, Marina K and Guillaume YL. (2012). Antibacterial activity of two bell pepper extracts:Capsicum annuum L. and Capsicum frutescens. International Journal Food Propriety, 15, 961-971.

[33] Norkaew O, Pitija K, Pripdeevech P, Sookwong P and Wongpornchai S. (2013). Supercritical fluid extraction and gas chromatographic-mass spectrometric analysis of terpenoids in fresh Kaffir lime leaf oil. Chiang Mai J. Sci, 40, 240-247.

[34] Chinn MS, Sharma-Shivappa RR and Cotter JL. (2011). Solvent extraction and quantification of capsaicinoids from Capsicum chinense. FoodBioprod.Process, 89, 340-345.

[35] Matta VM, Moretti RH and Cabral LMC. (2004). Microfiltration and reverse osmosis for clarification and concentration of acerola juice. Journal Food Eng, 61, 477-482.

[36] Cao GE and Prior RL. (1996). Antioxidant capacity of tea and common vegetables. Journal of Agricultural Food Chemistry, 44, 3425-3431. 
[37] Khokhar S and Apenten RKO. (2003). Iron binding characteristics of phenolic compounds: some tentative structure-activity relations. Food Chemistry, 81, 133-140.

[38] Farkas JO, Jakus and Hérberger K. (2004). Antioxidant activity relationships of flavonoids compounds. International Journal of Molecular Sciences, 9, 1079-1088.

[39] Esmaeili AK, Taha RM, Mohajer S and Banisalam B. (2015). Antioxidant Activity and Total Phenolic and Flavonoid Content of Various Solvent Extracts from In Vivo and In Vitro Grown Trifolium pratense L. (Red Clover). BioMed Research International, 1-11.

[40] Kuna A, Sahoo MR, Sowmya M, Mayengbam PD, Dasgupta M, Sreedhar M and Tholemfhuang S. (2018). Nutrient and Antioxidant Properties of Value Added King Chilli (Capsicum chinense) Products. Int. J. Curr. Microbiol. App. Sci, 7(6), 1-8.

[41] Emilio Alvarez-Parrilla, Laura A, De La Rosa, Shahidi F and Amarowicz R. (2011). Antioxidant Activity of Fresh and Processed Jalapeno and Serrano Peppers. Journal of Agricultural Food Chemistry, 59, 163-173.

[42] Aoyama S and Yamamoto Y. (2007). Antioxidant activity and flavonoid content of Welsh onion (Allium fistulosum) and the effect of thermal treatment. Food Sciences Technology Research, 13, 67-72.

[43] Scalbert A, Manach C and Morand C. (2005). Dietary Polyphenols and the Prevention of Diseases. Critical Reviews in Food Science and Nutrition, 45, 287-306.

[44] Sharififar F, Dehghn-Nudeh G, Mirtajaldini M. (2009). Major flavonoids with antioxidant activity from Teucrium polium L. Food Chem, 112, 885-888.

[45] Busaba T. and Lawan S. (2014). Phenolics, flavonoids and antioxidant activity of vegetables as Thai Side Dish. APCBEE Procedia, 8, 99-104.

[46] Khan RA, Khan MR and Sahreen S. (2012). Assessment of flavonoids contents and in vitro antioxidant activity of Launaea procumbens. Chemistry Central Journal, 6, 43.

\section{How to cite this article}

Oulaï AC, Djè KM, Eba KP, Adima AA and Kouadio EJP. (2018). Chemical composition, antioxidant and antimicrobial activities of Capsicum annuum var. annuum concentrated extract obtained by reverse osmosis. GSC Biological and Pharmaceutical Sciences, 5(2), 116-125. 